\title{
Issues in Implementing Broadband Powerline Communication Technology to Provide Internet Service - Case of LECO
}

\author{
R. L. Kumarasinghe and A .T.L.K. Samarasinghe
}

\begin{abstract}
Today internet is considered as the largest network of networks which provides various services to the people such as a mammoth source of information, source of entertainment etc. But most of the people don't get the opportunity to access internet due to a number of reasons. The lack of viable technologies to provide internet at lower cost is one of the main reasons faced by many countries in the world.
\end{abstract}

BPL is a widely discussed technology among world power distribution companies as a way of delivering broadband services to each and every home connected to power grid. Numerous field trials and limited deployments are underway in different parts of the world .Mass scale commercial role outs are yet to be initiated and many scholars have predicted, in future BPL will be preferred most as a "last mile" solution to provide internet services to homes.

In this research it is examined the issues pertaining to technology, infrastructure and standards in implementing BPL in Sri Lanka.

This research also presents recommendations, which may help to solve most of the identified issues.

Keywords: Internet, Broadband powerline communication

\section{Introduction}

Today, information plays a vital role in highly competitive business world as well as people's day-to-day activities. So, many companies and individuals attempt to access information using various methods such as newspapers, magazines, radio, television and internet. Among those, internet is considered as one of the quickest and fastest growing sources of information.

As the potential customer base for internet service is growing day by day, today there is a high potential for growth in the business of providing internet service.

\subsection{Broad band power line communication (BPL)}

Broad band power line communication is an emerging technology which can be used to provide Internet service to the consumers of electricity distribution companies.

As the future survival of distribution companies is uncertain, they are now searching new ways of revenue streams. Internet service through BPL is considered as a good option available for a new way of revenue generation.
LECO Board of Directors has identified implementation of Power Line Carrier Communication as a strategic objective for LECO, in the Corporate Plan for year 2007 - 2011.

Further LECO has entrusted Engineering, Research and Development Division of the Company with the functional goal of developing this project.

Even though a decision was made to go ahead with BPL project, a thorough study hadn't been done to asses the suitability of BPL technology to Sri Lanka

\section{Literature Survey}

\subsection{BPL}

BPL is defined as "Broadbandover Power Lines (BPL) also known as Power Line Communications (PLC) is a quickly evolving market that utilizes electricity power lines for the high-speed

Eng. R. L. Kumarasinghe, B.Sc (Eng). AMIESL, Presently, Electrical Engineer Lanka Electricity Company (Pvt)Ltd.,

Eng. A T L K Samarasinghe, B.Sc (Eng), MBA, C.Eng., MIESL, Head of the Department Electronics and Telecommunication Engineering of University of Moratuwa. 


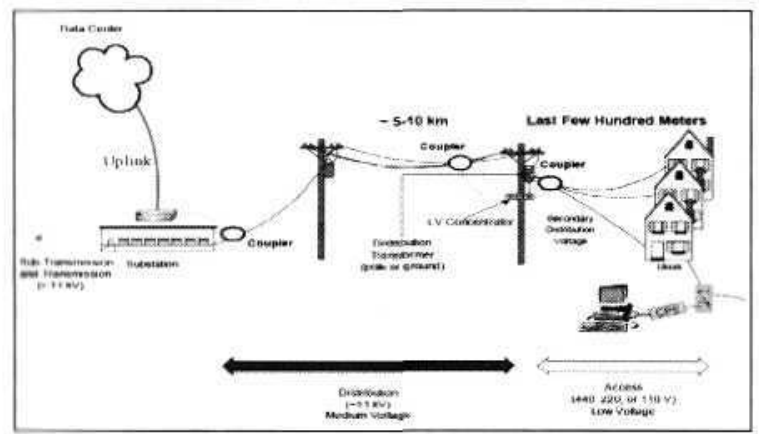

Figure 1- Generic BPL System Network

(Source www.caslon.com.au/powerlinenote.htm)

transmission of data services. The new low-power, unlicensed BPL systems couple radio frequency energy onto the existing electric power lines to provide high-speed communications capabilities." Federal Communications Committee USA (2004) [1]

\subsection{Technology}

BPL enables networking machines within a building. It provides broadband connection in every socket in every room making it possible to network all kinds of common appliances in a household.

Advantages and disadvantages of BPL technology have been identified by different scholars.

\subsection{Advantages}

There are 3 major benefits of BPL deployments, namely, increasing the availability of broadband services to homes and businesses; improving the competitiveness of the

broadband services market; and, improving the quality and reliability of electric power delivery. R.W. McCaughern (2005) [2].

BPL offers to the residential and the business customers not only voice, video, and data services but also others such as mapping and home management abilities that work more reliably and faster than in the past (Wilt, 2004) [3].

\subsection{Disadvantages}

\subsubsection{Potential for interference}

Some groups oppose the proliferation of this technology, mostly due to its potential to interfere with amateur radio transmissions. As power lines are typically untwisted and unshielded, they are essentially large antennas, and will broadcast large amounts of radio energy. Because of their lack of shielding, the BPL systems are also at risk of being interfered with by outside radio signals.

Another disadvantage, due to the signal losses that take place in a wire, is their high attenuation and such there is a need for repeaters at regular intervals Breen (2004) [4]

\subsection{Deployment of BPL around the world}

A number of foreign governments including Australia, Austria, China, Finland, Hong Kong, Hungary, Ireland, Italy, Korea, Japan, Netherlands, Poland, and Switzerland are currently studying BPL technology or have permitted equipment trials. The outcomes have shown mixed results and have led some administrations to ban BPL systems while other administrations have allowed deployment under various conditions.

\subsection{Financial viability}

Power Line Carrier (PLC) Communications have been heralded as the "3rd wire" to every home. Recent activity has indicated this technology is just on the threshold for achieving commercialization, with numerous pilot trials, demos, and limited deployments underway in the US and abroad. While the technical challenges to building PLC systems are being addressed, there has been little public analysis of the techno-economic case for PLC systems Rahul Tongia (2004)[6]

\section{Analysis}

Successful technology implementation will depend on various factors. Technology, Standards \& regulations, Internet Service providers, Project Financing, Infrastructure and many more factors will affect the success of BPL implementation and many issues are also associated with those factors.

In this research, it was attempted to identify only the key issues relating to technology, standards and infrastructure in implementing BPL in LECO operational area. 


\subsection{Issues Identified-Technology}

\subsubsection{Commercial attractiveness relative to other internet delivery mechanisms}

There are number of technologies other than BPL available in the world to provide internet service namely, Digital Subscriber Line (DSL), Cable Modem, Fiber, Wireless Wi-Max, Wi-Fi \& Satellite.

Access to internet using any of the above technologies is possible in Sri Lanka and the charges are competitive with respect to the speed of the connection. LECO will have to face considerable competition when BPL Project is launched.

\subsubsection{Technology capability of LECO}

When a BPL system is installed on the top of a distribution network, it will be a part and parcel of the distribution system. For the smooth operation of on BPL system, the distribution system should be well maintained and it must function smoothly. The success of BPL project will depend on how efficiently and effectively LECO manages its distribution system and related functions.

\subsubsection{Vendor Selection}

There are many venders in the world. LECO has experienced that some of the leading BPL equipment manufacturers were not interested when calling for proposals to implement a pilot project in LECO operational area. As this is an emerging technology a proper vendor has to be selected in order to implement a successful pilot project and then to commercial-rollout. The failure to select a proper vendor may result in poor technology transfer and waste of capital.

\subsubsection{Effective mechanism for Technology Transfer}

BPL is a novel technology to LECO. LECO is inexperienced in this technology and neither are the local experts. In order to successful implementation and operation of the BPL project, technology has to be transferred effectively.

A Joint Venture with an Equipment supplier to purchase the equipment from the supplier or to get Expert Service from an independent body are two main options which LECO can consider to get the technology transferred.

\subsubsection{Consumers fear}

To connect to the internet using BPL technology, one has to plug in a BPL modem to a power socket and connect the other end to a computer. During pre-feasibility, many consumers were doubtful the about the level of safety in this method.

\subsubsection{High cost of BPL equipments}

The cost of BPL equipment is considerably high and this cost would be a key factor in deciding whether to proceed with the project or not.

\subsection{Issues Identified-Infrastructure}

\subsubsection{Dependency on CEB}

LECO purchase Electricity from CEB from 30 primary substations .CEB operates and manages those 30 primary substations. The Reliability of LECO power depends on the reliability of the CEBpower.

A Primary Substation is the ideal location to connect $11 \mathrm{kv}$ system to the internet backbone and a few types of equipment needs to be mounted at the PSS to monitor internet service. But PSS are governed by CEB. Institutional conflict may arise when addressing this issue.

\subsubsection{Experience as an ISP}

Internet Service provision will be an entirely a new experience for LECO. LECO may face several technical as well as managerial challenges when acting as an ISP.

\subsubsection{ISP Partner.}

LECO needs to get internet service connection from an ISP to provide internet service to consumers. In Sri Lanka there are many ISP providers such as Sri Lanka Telecom, Dialog and Suntel.

LECO will need to select one or more ISP to inject internet signal to $11 \mathrm{kV}$ system. Above ISP service providers will also be LECO's competitors in future. ISP Charges will also be another decisive factor for the successful implementation of the BPL project. 


\subsection{Infrastructure-Consumer}

\subsubsection{High cost of BPL Modem.}

A consumer BPL modem costs approximately USD 165 whereas modems of other competitive technologies are available at USD 70-100. Because of the high cost of BPL modems, consumers may not wish to get internet service through BPL technology.

Following graphs show the findings of the survey carried out to identify the infrastructure availability of LECO consumers

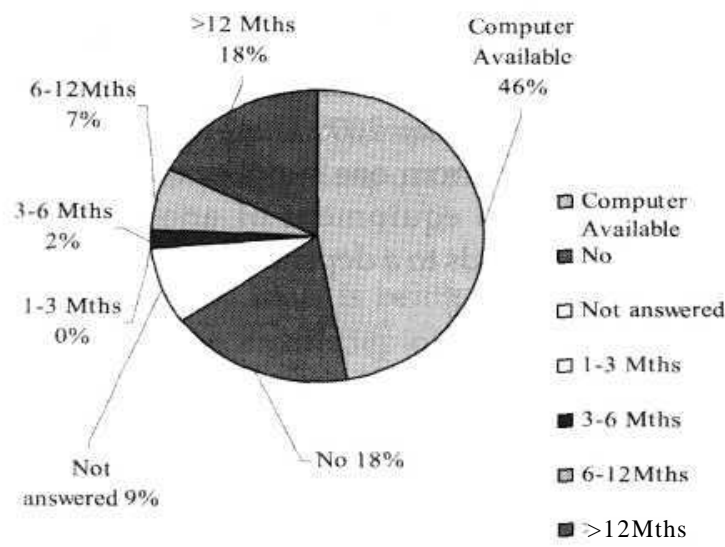

Figure 2- consumer Computer Availability \& intend to buy

\subsubsection{Computer availability \& Intention to buy}

A Computer is a basic requirement to access internet. There is no point of implementing BPL if the consumers don't posses the basic requirement. According to the survey only $46 \%$ of the consumers posses computers. $18 \%$ of consumers will not buy computers in the near future and $9 \%$ of the consumers have not answered for that specific question in the questionnaire. Others have indicated their willingness to buy a computer within the next 1 3 months; 3-6 months, 6-12months and over 12 months. In the worst case scenario if all the unanswered consumers are not going to buy computers in there near future, then $27 \%$ of the customer base will be out of these potential broadband target group. As per the data, that implies that the LECO consumer base having computers will be growing and the figures are satisfactory.

\subsubsection{Internet Availability \& intention to buy}

According to the results, from the total number of consumers, $28 \%$ of consumers would not get

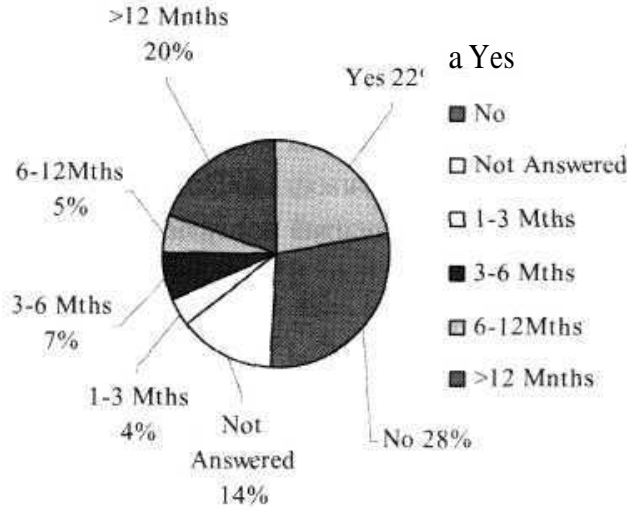

Figure 3- Consumer Internet Availability \& intend to buy

internet connection.14\% have not answered. Then only $58 \%$ of consumers would be the prime target for BPL. $22 \%$ of consumers already have internet connections and assuming that they are not willing to change their existing internet connection to BPL immediately, it can be assumed that the potential customer base would be $36 \%$ at the beginning.

\subsubsection{Monthly Internet Bill

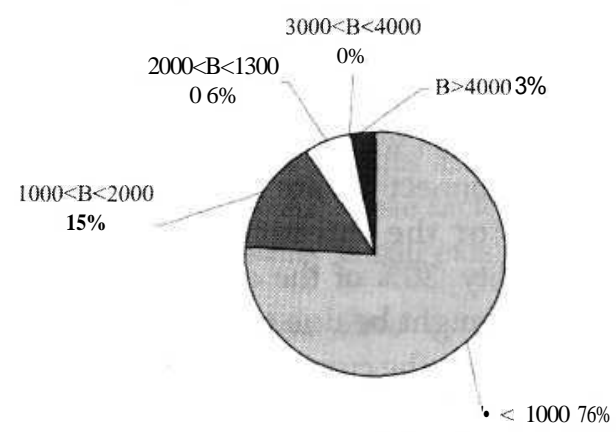

Figure 4 -Consumer monthly internet bill

$76 \%$ of those who have an internet connection pay less than Rs.1000.00 as their monthly internet bill. When pricing the internet service this has to be taken into consideration, as internet service at higher price than Rs.1000.00 may not attract the consumers who fall in to the above category.

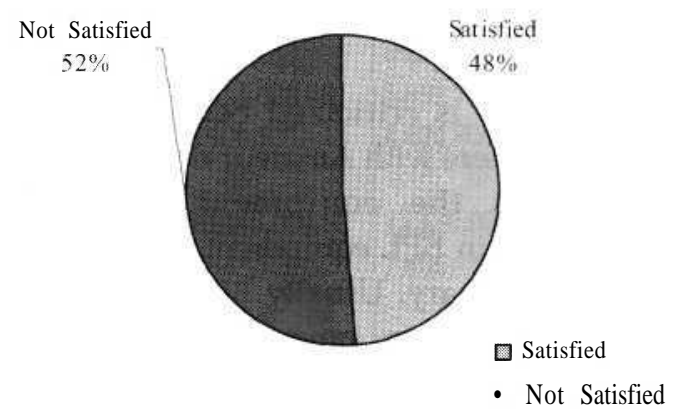

Figure 5 -Consumer internet service satisfaction 


\subsection{5}

$52 \%$ of those who already have an internet connection are not satisfied with the connection. If BPL offers better service, LECO can capitalize on this dissatisfaction and a higher percentage out of $52 \%$, might shift to BPL.

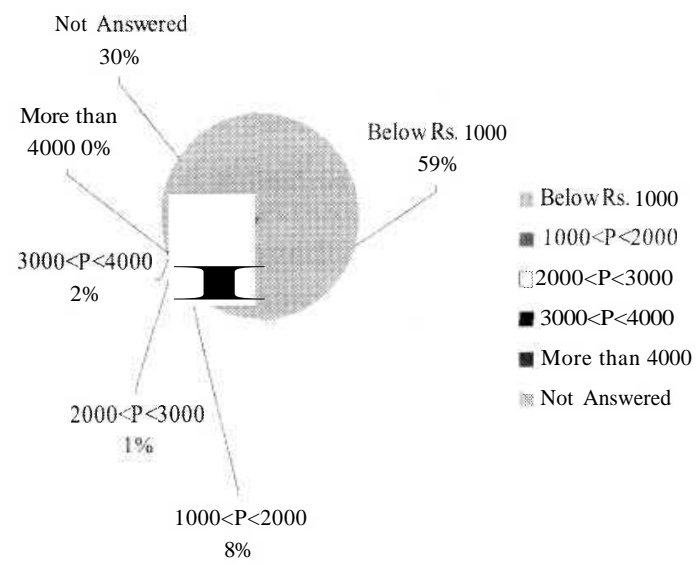

Figure 6- Amount Consumer willing to pay as monthly internet bill

\subsubsection{Amount Consumer willing to pay as Monthly Internet Bill}

$59 \%$ of consumers who already have or expect to get internet connection, are willing to pay below Rs.1000.00 for the internet service with the desired quality. $30 \%$ of the consumers have not answered. It might be due to consumer's lack of awareness about the current internet charges.

\subsection{Issues-Standard/Regulation}

\subsubsection{Getting the License to provide Internet Service}

LECO needs to get a license to provide internet service. LECO has its capability in power distribution but not as an ISP. In order to get the license, credentials need to be proved.

\subsubsection{Regulation Limitations}

\subsubsection{Interference}

BPL Technology is criticized because of it's potential to interfere with Amateur radio signals. Depending on the equipment suppliers technology used in BPL equipment, the level of interference may vary. Usually BPL equipment operate in the frequency range of 3-40 MHz. In Sri Lanka this frequency range is allocated to aeronautical mobile, maritime mobile, amateur radio, fixed line etc. If significant interference results from BPL equipment, significant objections may arise from amateur radio operators and other operators.

In other countries, regulatory authorities have imposed interference restrictions but in Sri Lanka still there is no regulation for interference control. If BPL is implemented, competitors and radio operators may complain to authorities (TRC) about interference levels. In future regulations might be enforced to restrict interference levels.

\subsubsection{Global standards}

According to the BPL literature, global standards don't exist for BPL equipment and IEEE is planning to declare global standards for BPL equipment in the year 2008.There might be an issue; Equipment from one supplier may not be compatible with equipment of another BPL vendor, which leads to a dependency on one BPL vendor.

\subsection{Financial viability}

The Financial viability of the BPL project will mainly depend on following factors.

- Cost of BPL equipment and technology transfer

- Monthly fee for internet backhaul

- Operational \& Maintenance costs

- Monthly Internet Service charge of the consumers

- Penetration which BPL would be able to achieve.

Table 1 shows the NPV(Net Present Value) of the BPL pilot project proposal forwarded by one of the world leading BPL equipment Manufacturer. Following assumptions were also made.

- ISP cost will be reduced by $10 \%$ each year

- Maintenance and other cost will increase by $10 \%$ per year

- $20 \%$ initial penetration and grows which will by $10 \%$ each year

- LECO will provide Internet service @ 1500.00 fixed per month

- $10 \%$ discount rate

- Only the domestic consumers are considered

- BPL equipment fall under $6 \%$ duty category

- ISP (Backhaul charge per month is taken from leading ISP in Sri Lanka) 
According to the table NPV of the project is negative when next 5 years is considered. High BPL equipment cost and backhaul charges are the main contributors for the negative NPV.

A project to be financially viable, it should produce positive NPV within the considered project duration. NPV of this project proposal can be made positive only if LECO is able to achieve high penetration which seems difficult under the present highly competitive environment.

\section{Conclusion}

Broadband over power line technology, once confined to the laboratories of technologists, is now viewed by many experts as a fast growing and potentially important player in the broadband market.

A Number of trials is being conducted around the world in small deployments and in some cases results are attractive. In few countries pilot projects have been abandoned due to financial viability issues or inability to meet emission restrictions. Still, large scale deployments are yet to be initiated.

Global standards are yet to be established for the BPL equipment. Many organizations have been formed to study the viability and the suitability as an option for last mile solution for internet service.
Some experts believe BPL is the best solution to avoid the digital division of the world. But interference is a major concern of this technology and ham radio operators are the main opposition for the proliferation of BPL.

In Sri Lanka neither LECO nor CEB has done a pilot project on BPL but Dialog Telekom has used BPL technology to provide internet service to few corporate customers.

In recent past both LECO and CEB are interested in implementing a pilot project. LECO has taken a step further and now in the process of negotiating with few equipment suppliers

From the LECO's point of view, equipment cost will play a major role in deciding whether to proceed with the BPL project or not and the BPL project will be testing the negotiation capabilities of LECO.

LECO may face significant competition as there are many competitive technologies available in Sri Lanka and they have started commercial deployment of these technologies. But according to the consumer survey, consumers posses basic infrastructure requirements and demand for internet is growing. All those factors imply that window of opportunity is still exist for BPL.

$P V^{*}$-Present value to year Zero

Table 1 Financial Vaibility-1(All costs are in Sri Lankan Rupees)

\begin{tabular}{|c|c|c|c|c|c|c|}
\hline IYear Investment & 0 & 1 & 2 & 3 & 4 & 5 \\
\hline Equipment & $33,022,500.00$ & & & & & \\
\hline Technology Transfer fee & $70,988.37$ & & & & & \\
\hline Duty & $9,576,525.00$ & & & & & \\
\hline Clearance & $300,000.00$ & & & & & \\
\hline & $42,970,013.37$ & & & & & \\
\hline ISPCharges (C-Link) & & $7,992,000.00$ & $7,192,800.00$ & $6,473,520.00$ & $5,826,168.00$ & $5,243,551.20$ \\
\hline Maintenance & & $50,000.00$ & $55,000.00$ & $60,500.00$ & $66,550.00$ & $73,205.00$ \\
\hline Other Cost & & $50,000.00$ & $55,000.00$ & $60,500.00$ & $66,550.00$ & $73,205.00$ \\
\hline Costs for respective years & $42,970,013.37$ & $8,042,000.00$ & $7,247,800.00$ & $6,534,020.00$ & $5,892,718.00$ & $5,316,756.20$ \\
\hline $\mathrm{PV}^{*}$ for respective years(Costs) & & $7,310,909.09$ & $5,989,917.36$ & $4,909,105.94$ & $4,024,805.68$ & $3,301,287.29$ \\
\hline Total NPV(Costs) & $68,506,038.73$ & & & & & \\
\hline Income & & $8,640,000.00$ & $9,450,000.00$ & $10,440,000.00$ & $11,430,000.00$ & $12,600,000.00$ \\
\hline PV for respective years(Income) & & $7,854,545.45$ & $7,809,917.36$ & $7,843,726.52$ & $7,806,843.79$ & $7,823,608.67$ \\
\hline Total PV(Income) & $39,138,641.80$ & & & & & \\
\hline NPV & $(29,367,396.93)$ & & & & & \\
\hline
\end{tabular}




\section{Recommendations}

Following recommendations can be proposed to LECO in order to overcome the issues and make BPL a reality in Sri Lanka.

\subsection{Technology:}

As a number of competitive technologies exist to provide internet service LECO needs to price the Internet Service at the right price with the right speed to have an enough penetration.

LECO can use its own staff as marketers as every month Revenue officers (Meter Readers) visit every house hold connected to LECO.

A Suitable vendor should be identified for effective implementation of the BPL project .If more than one proposal is received LECO needs to fully evaluate the project proposals with the emphasis on the following factors, the duration the suppliers has been in BPL business, Suppliers BPL project experience .(overseas/ Local),BPL Equipment cost, suitability to LECO distribution system., Performance certificate from utilities which supplier has sold BPL equipment \& Compliance of the other countries emission restrictions.

The best mechanism fortechnology transfer will be a Joint venture as BPL is a totally new technology to Sri Lanka

To overcome the consumers fear of using same power cable to access internet, LECO needs to carry out an aivureness campaign and the high equipment cost can be solved by having large consumer penetration $\&$ by going for cheaper products.

Large penetration can be achieved through an aggressive marketing campaign while providing satisfied internet service at the right price. Going for cheaper products will depend on supplier selection. Supplier selection is not only based on the price of BPL equipments. As mentioned previously it involves several criteria. The Second option most probably has to be abandoned.

\subsection{Infrastructure}

LECO has no experience as an Internet Service Provider (ISP). Consulting relevant experts, Recruiting experienced and qualified people to
ISP operations or a joint venture $0 \mathrm{~V}$ ) with an ISP would be the options to try out to over come this issue.

JV with an existing ISP will reduce the risk of being novel in providing internet service but another issue arises in selecting the right ISP as there are a sevens ISP s in Sri Lanka. In selecting the ISP, ISP charges and reliability of the service has to be considered. ISP charge has a direct influence in pricing the service.

Improvement in source supply quality and reliability can be achieved through negotiating with CEB to get a reliable power supply and to get CEB approval to install required equipment in Primary Substations.

A Successful BPL pilot project initiated by LECO would be a perfect example for CEB as it is also interested in BPL implementation in CEB operational areas. LECO may need to convince CEB that by allowing LECO to install BPL equipment at PSS CEB also will be benefited in future.

\subsection{Standards/Regulations}

The License will be an issue only if the license application is rejected by the TRC. In that case, a joint venture may be established with an existing ISP. As stated previously, LECO needs to connect $11 \mathrm{kV}$ system to an existing ISP in order to convert llkV system to an internet backbone. If a joint venture is established with the same ISP license holder, the issues can be solved.

Issues associated with interference can be solved or minimized by adopting following recommendations. When selecting a BPL vendor, as emission restrictions do not exist in Sri Lanka at the moment, compliance to interference limitations in other countries should be chosen as a selecting criteria, Use Fiber optics or other methodology as $a$ backbone in locations high interference levels are observed, Identify the interfered frequencies and interact with equipment supplier to find ways to minimize interference.

LECO may also attempt to establish a subsidiary for BPL and get the BOI status 


\section{Reference}

1. Prof. Ananda Jayawardene, (2006) Department of Management of Technology (DMOT) (2005/2007) MN 5211- International Technology Transfer, In:, Unit 2 - Technology Components, Technological Capabilities and Technology Transfer Models for Effective Technology Transfer, University of Moratuwa, Sri Lanka.

2. Hemachandra, D.G., (2004), "Success and failure of Sri Lanka Railways in International technology transfer", Unpublished MBA-MOT Research, University of Moratuwa.

3. LECO Management Information System Reports July-2007

4. Manage, PBN (2005)"Applicability of Broad Band Services to house holds in Sri Lanka" Unpublished MBA-MOT Research, University of Moratuwa.

5. Wanniarachchi, S. (2005) "Asymmetric Digital Subscriber Line as an internet Super high way for Sri Lanka". Unpublished MBA-MOT Research, University of Moratuwa.

6. Wejaysantha, P.B.M. (2006) "Utilization of Communications Systems in CEB" Unpublished MBA-MOT Research, University of Moratuwa.

7. http://www.ambientcorp.com/ visited on 11/ $09 / 07$
8. http://www.arrl.org/ visited on 15/08/07

9. http://www.bandeeni.com/4s 7 of.htmvisited on 03/08/07

10. http://www.caslon.com.au/ visited on $-20 / 10 /$ 07

11. http://www.centerpointenergy.com/ visited on 03/08/07

12. http://www.corinex.com visited on 12/10/07

13. http://www.currenttechnologies.com visited on $20 / 08 / 07$

14. http://www.fcc.gov/cgb/ visited on 15/08/07

15. http://www.ist-opera.org/visited on 05/07/07

16. www.leco.lk visited on $15 / 08 / 07$

17. http://www.mainnet- visited on 15/09/07

18. http://www.mcmc.gov.my/mcmc/visited on 17/08/07

19. www.ntia.doc.gov visited on 16/08/07

20. http://strategis.ic.gc.ca/epic/site/smt-gst.nsf/ vwapj/bpl-e.pdf/\$FILE/bpl-e.pdf visited on 25/ 09/07

21. http://tprc.org/papers/2003/246/TongiaPLC.pdf visited on 15/10/07 visited on 17/08/07

22. www.trc.gov.lk visited on $15 / 08 / 07$ 